\title{
Estudo comparativo da cadeia produtiva florestal das Regiões de Lages e de Pelotas: uma visão sistêmica do desenvolvimento regional
}

\author{
Sandro al-Alam Elias* \\ Regis Rathmann ** \\ Denise Barros de Azevedo*** \\ Alberto Silva Dutra" \\ Tânia Nunes Silva ${ }^{\# \#}$
}

\section{A comparative study of the forest productive chain of the Lages and Pelotas regions: A systemic view of the regional development}

\begin{abstract}
RESUMO
Pretende-se comparar o setor de base florestal em duas regiões do Sul do Brasil: a de Lages/SC e a de Pelotas/RS. Nesse viés investigativo, busca-se analisar o desenvolvimento regional inserido no contexto sistêmico da cadeia produtiva florestal, com o intuito de visualizar as perspectivas das Regiões de Pelotas e de Lages. A Região de Lages apresenta-se instalada a montante e a jusante da cadeia produtiva florestal, enquanto a de Pelotas encontra-se em fase embrionária de desenvolvimento. Para a Região de Lages, o setor florestal é a principal atividade dos últimos cinquenta anos. No que tange à Região de Pelotas, é necessário aguardar os novos posicionamentos, a fim de poder definir os cenários futuros do setor de base florestal.
\end{abstract}

Palavras-chave: cadeia produtiva florestal, desenvolvimento regional, estudo comparativo.

\footnotetext{
ABSTRACT

This paper aims to make a comparison of two South regions' forest base in Brazil, the regions of Lages/SC and Pelotas/RS. The analysis focuses on the regional development inserted in the forest productive chain systemic context with the intention to visualize the perspectives of the Pelotas

Recebido em 11.09.2008. Aceito em 22.10.2008.

* Mestre em Agronegócios. PPG-Agronegócios/Cepan/Ufrgs. Rua Santos Dumont, 621, Centro, 96015-010, Pelotas, RS, Brasil. E-mail: saaelias@uol.com.br.

** Doutorando em Planejamento Energético. Centro de Tecnologia da Universidade Federal do Rio de Janeiro. Bloco C, Sala 211, Cidade Universitária, 21941-972, Rio de Janeiro, RJ, Brasil. E-mail: rrathmann@ ea.ufrgs.br.

*** Doutoranda em Agronegócios. PPG-Agronegócios/Cepan/Ufrgs. Rua Washington Luís, 855, 90010-460, Porto Alegre, RS, Brasil. E-mail: deniazevedo@hotmail.com.

\# Mestre em Agronegócios PPG-Agronegócios/Cepan/Ufrgs. Av. Getúlio Vargas, 2189, apto. 302, Centro, 98802000, Santo Ângelo, RS, Brasil. E-mail: alberto.dutra@bol.com.br.

\#\# Doutora em Sociologia (USP), professora adjunto 4 da EA/CEPAN/UFRGS. Rua Washington Luiz, 855, Centro, 90010-405, Porto Alegre, RS, Brasil. E-mail: tnsilva@ea.ufrgs.br.
} 
Elias, Sandro A.; Rathamann, Regis; Azevedo, Denise B.; Dutra, Alberto S.

Estudo comparativo da cadeia produtiva florestal das regiões de Lages e de Pelotas...

and Lages regions. The Lages region presents itself in the upstream and downstream of the forest productive chain, whilst the Pelotas region is in embryonic phase of development. The conclusion is that for the Pelotas region it is necessary to wait for the new positions in order to define the future scenes of the forest base sector. And for the Lages region, the forest sector is the main activity of last fifty years.

Key words: forest productive chain, regional development, comparative study.

JEL Classification: C32, C52, E31, E51, E52.

\section{Introdução}

As mais recentes publicações indicam que a área florestal mundial tem se reduzido a uma taxa anual de 2,4\%, ou seja, algo em torno de $90.000 \mathrm{~km}^{2}$ a menos de cobertura florestal a cada período. É apontada, como principal fator causador desse decréscimo, a conversão de áreas florestais para práticas de atividades agropecuárias (United Nations, 2005, p. 12). Diante desse contexto, tem destaque, no Brasil, o setor florestal, o qual, segundo Freitas (2005), é o terceiro em área plantada no país no ano de 2004, perdendo apenas para o plantio de milho e soja. Destaca-se a participação da Região Sul, a qual representa $26 \%$ do volume total plantado no país, sendo o Paraná o estado com a área mais representativa, seguido de Santa Catarina e Rio Grande do Sul. Têm-se as florestas de eucalipto ainda como preponderantes entre as florestas comerciais no Brasil, porém, na região citada, destaca-se o plantio de pínus, o qual está diretamente correlacionado à condição edafoclimática adequada à produção dessa espécie.

Mais do que isso, as áreas plantadas vêm crescendo, ao longo do tempo, na região e apresentam como incentivadores dois aspectos: (i) a taxa de crescimento anual da demanda, e (ii) a projeção de um déficit entre a oferta e a demanda de madeira nos próximos anos. A primeira é estimada em uma taxa de $2,74 \%$ na região, enquanto a segunda deriva de um aumento da demanda industrial, superior à taxa de crescimento da oferta, tanto para fins de produção de papel e celulose, quanto para a geração de energia (Freitas, 2005).

Somam-se aos fatores acima citados as vantagens comparativas do Brasil em relação a outros países tradicionais na produção de madeira como: maior crescimento das florestas, 
tecnologia de produção e de processamento desenvolvidas, cadeias florestais estruturadas e baixo custo de produção (Abraflor, 2006). Tais informações servem para ressaltar a importância deste setor produtivo para o país e para explicar os recentes investimentos das empresas de celulose e papel na aquisição de terras e plantio de florestas. De igual modo, servem para justificar os projetos de instalação e ampliação dessas indústrias na região conhecida como Metade Sul do Rio Grande do Sul, a qual se encontra em dificuldade em termos econômicos e sociais (SCP/RS, 2002).

Nesse contexto, pretende-se efetuar um estudo comparativo entre uma região na qual o setor de base florestal já esteja implantado (Campos de Lages/SC), com outra onde esse seja incipiente (Pelotas/RS) e, mais do que isso, onde não exista a tradição de produção nessa cadeia produtiva. Pretende-se, com isso, responder aos seguintes questionamentos: (i) a cadeia que vem se desenvolvendo na Região de Pelotas é semelhante àquela que se desenvolveu na Região dos Campos de Lages?; (ii) além disso, em termos de desenvolvimento regional, é possível transpor os resultados da inserção da cadeia de base florestal da primeira para a segunda região?

Pode-se observar, preliminarmente, que a cadeia de base florestal que está sendo configurada na Região de Pelotas é diferente, em virtude de suas especificidades regionais, e, em função disso, os resultados não podem ser perfeitamente transmutáveis entre regiões. Objetiva-se, assim, investigar essa afirmação mediante a resposta ao objetivo deste estudo, qual seja: cenarizar a cadeia produtiva de base florestal de Pelotas/RS, em comparação com a cadeia produtiva de base florestal instalada na Região dos Campos de Lages/SC, bem como analisar as similaridades, em termos de perspectiva de potencialidades do desenvolvimento regional da Região de Pelotas/RS.

Inicialmente, serão contextualizadas as experiências dos estados de Santa Catarina, e, mais recentemente, do estado do Rio Grande do Sul. Após, serão revisados os referenciais teóricos utilizados na análise dos resultados deste estudo. Como referencial teórico, são empregados os pressupostos da Análise de Cadeias Produtivas Agroindustriais (CPA) e o de Filiére (cadeia produtiva escola francesa), de forma que seja possível desenhar a cadeia produtiva da Região de Pelotas, e também compará-la àquela existente na Região dos Campos de 
Elias, Sandro A.; Rathamann, Regis; Azevedo, Denise B.; Dutra, Alberto S.

Estudo comparativo da cadeia produtiva florestal das regiões de Lages e de Pelotas...

Lages/SC. Por fim, são avaliadas as contribuições acerca do desenvolvimento regional e local, de forma que se possa efetuar a comparação dos diferentes condicionantes, resultados e perspectivas da implantação do setor nas regiões avaliadas, e são abordados aspectos da análise sistêmica.

\section{O setor de base florestal na Região Sul do Brasil}

A Região Sul apresenta superfície total de 576,3 mil km² (57,6 milhões de hectares) e cobertura nativa remanescente de 12,5 milhões de hectares. Além dessa cobertura nativa remanescente, essa região se destaca pelas florestas plantadas; concentrava, em 2002, cerca de $28 \%$ do total das florestas plantadas no Brasil (SBS, 2003). Tendo em vista a proximidade, as condições de clima e as características regionais, optou-se por desenvolver este trabalho utilizando as regiões dos Campos de Lages, em Santa Catarina, e Região Sul do Rio Grande do Sul.

\subsection{O setor de base florestal e os aspectos da Região dos Campos de Lages em Santa} Catarina

Na Região da Serra Catarinense, está inserida a Região dos Campos de Lages. É assim classificada conforme o Programa das Nações Unidas para o Desenvolvimento (PNUD, 2006). Por consequência, o Município de Lages / SC passou a experimentar um impulso econômico em todos os campos de atividade, motivado pelo o desenvolvimento da indústria madeireira naquela região, principalmente, a partir de 1910.

De acordo com Costa (1982), essa atividade ultrapassou, em significância econômica, a indústria agropecuária durante as décadas de 1950 e 1960, atividade dominante desde sua fundação. Cabe salientar, de acordo com Hoff e Simioni (2005), que o desenvolvimento do setor madeireiro nessa região se inicia no período em que está ocorrendo o esgotamento das reservas de madeira do Estado de Santa Catarina, essas baseadas em florestas nativas, dentre elas, a Araucária Angustifólia. Nesse sentido, verificou-se a migração de madeireiros gaúchos e de pessoas que exploravam madeira no oeste de Santa Catarina para o planalto serrano catarinense. 
Esse fato justifica a predominância de empresas familiares na indústria da madeira daquela região.

Todo o movimento em torno da madeira fez com que surgissem, na região, um conjunto de atividades econômicas relacionadas à extração de madeira, como o comércio de autopeças para caminhões, pequenas marcenarias, fábricas de caixas, de móveis, de laminados e compensados, de papel, de papelão e de pasta mecânica (Hoff e Simioni, 2005). A indústria madeireira vive seu período áureo durante a década de 1960, quando o município de Lages, segundo Gourlati Filho (2002), respondeu por 12\% do ICM arrecadado no estado de Santa Catarina. Nos países europeus, devido à necessidade de otimizar a exploração florestal, devido à extensão das áreas de floresta, a extração e o processamento da matéria-prima madeira se dá de maneira mais racional, com ênfase na utilização máxima de todos os resíduos e sobras. Já no Brasil, a preocupação com o reflorestamento, na Região dos Campos de Lages, bem como a utilização das sobras de madeira para a transformação em produtos de alto valor agregado ocorreu quando suas reservas de madeira estavam por acabar (Brand e Neves, 2005). Assim, as décadas de 1970 e 1980 representaram um período de grave crise econômica para a região, em vista do esgotamento da matéria-prima, fato que acarretou uma desarticulação na indústria de base florestal.

Com o fomento de incentivos governamentais, geraram-se, em meados da década de 60, iniciativas de reflorestamento, principalmente com a espécie de pinus. A madeira dessa espécie pode ser totalmente extraída com, aproximadamente, 20 anos de idade. Isso explica o reaquecimento do setor florestal naquela região, a partir de meados da década de 1980, mas, sobretudo, a partir de 1990 (Hoff e Simioni, 2005).

Pode-se observar ainda, conforme a Figura 1, a diversidade da Cadeia Produtiva Florestal e de Madeira da Região de Lages/SC. De acordo com Bacha (2000), estão compreendidas todas as atividades a montante e a jusante. Essas interligam-se tecnicamente, ou seja, existe a efetividade na cadeia instalada e na coordenação entre os elos que a compõem. 
Elias, Sandro A.; Rathamann, Regis; Azevedo, Denise B.; Dutra, Alberto S.

Estudo comparativo da cadeia produtiva florestal das regiões de Lages e de Pelotas...

A Região dos Campos de Lages é composta por 18 municípios. Tal região demonstra considerável crescimento do número de empresas ligadas ao processamento de madeira, no ano de 2002, em relação ao ano de 1980. Destaca-se, nesse contexto, a recente instalação, no município de Lages, de uma unidade de geração de energia da multinacional Tractebel, que usa os resíduos das empresas madeireiras para a geração de energia e vapor. Com o aproveitamento dos resíduos das madeireiras (cavaco de madeira, serragem, maravalha, casca de madeira), a unidade de Lages da Tractebel equaciona, naquela região, um dos problemas ambientais comuns aos polos madeireiros. Esses problemas ambientais são causados pela queima dos excessos de resíduos de madeira, a qual polui a atmosfera, ou pelo depósito dessas sobras, queimadas ou não, no solo, em condições impróprias. Esses comportamentos causam a contaminação dos solos e do lençol freático.

A seguir, a Figura 1 mostra como acontece a cadeia produtiva florestal e de madeiras na Região dos Campos de Lages.

Figura 1: Cadeia produtiva florestal e de madeiras da Região dos Campos de Lages (Santa Catarina).

Figure 1: Forest productive chain and woods of the region of Campos de Lages (Santa Catarina).

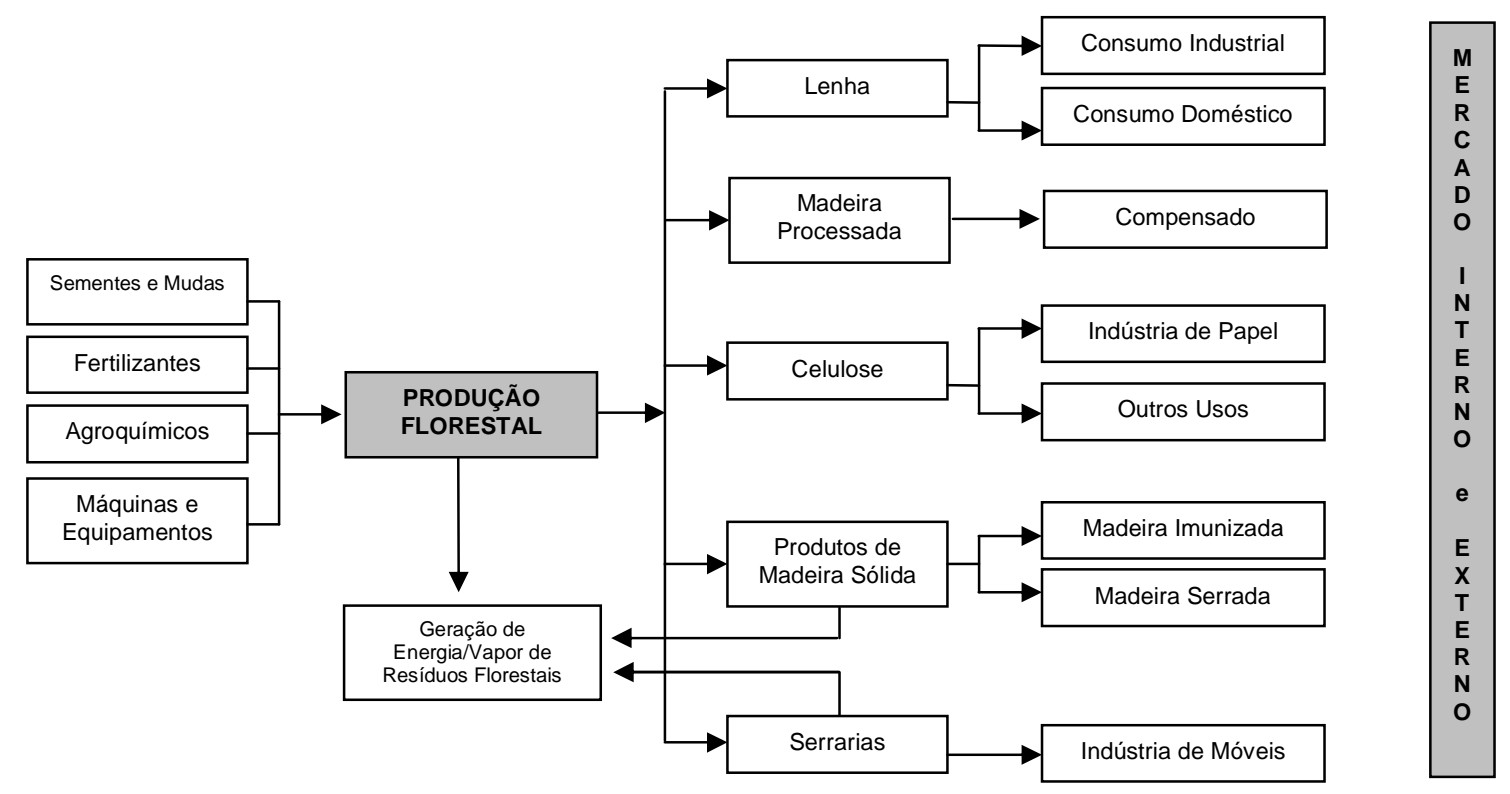

Fonte: Adaptado de ABRAF (2006).

Apresentada a figura sobre o fluxo produtivo florestal e de madeiras nos Campos de Lages, é essencial lembrar um outro agente que atua nessa cadeia: a Universidade do Planalto 
Catarinense (UNIPLAC). Essa instituição conta com um moderno laboratório e um quadro de pesquisadores especializados no setor. Eles atuam no desenvolvimento de pesquisas que perpassam desde aspectos técnicos, relacionados às diversas espécies de madeira, produtos e processos inerentes ao seu tratamento e processamento, até a realização de estudos que abordam os mais diversos temas relacionados à cadeia produtiva da madeira daquela região.

A microrregião Campos de Lages apresentou significativas melhorias em alguns índices de desenvolvimento humano, medidos pelo PNUD nos anos de 1991 e 2000. Esse fato reforça a hipótese de que o novo impulso, verificado com a reorganização da indústria de base florestal no início da década de 1990, contribuiu significativamente para o desenvolvimento regional.

\subsection{O setor de base florestal e os aspectos de Pelotas/RS}

A Região Sul do Rio Grande do Sul, onde se localiza o município de Pelotas, cidade polo dessa região, não possui tradição na exploração de florestas plantadas. Após o anúncio da instalação de uma indústria de papel e celulose, prevista para entrar em funcionamento em 2011, com investimento estimado em R \$ 1,3 bilhões de dólares e aquisição de 200.000 hectares de terra, a região busca preparar-se para essa nova atividade que está sendo introduzida (VCP, 2006).

Diferente dos demais estados da Região Sul, o Rio Grande do Sul possui algumas particularidades em relação à formação florestal. Rambo (1956) divide o estado do Rio Grande do Sul em duas formações vegetais: (i) a do campo e (ii) a da floresta. Da área total do estado, cerca de $131.896 \mathrm{~km}^{2}$ (46,26\%) era campo; 98,327 km² (34,47\%), mata; o restante, vegetação litorânea com banhados inundáveis e outras formações. Portanto, dois terços da área do Estado foram originalmente ocupados pela formação campestre, uma paisagem de estepe, porém num ambiente de clima caracterizado por umidade alta.

Essa situação se reflete na concentração das indústrias de base florestal na metade norte do estado, em função, inicialmente, da exploração da floresta nativa. Por não possuir tradição na exploração de florestas, diferentemente de outras regiões florestais, na Região de Pelotas 
Elias, Sandro A.; Rathamann, Regis; Azevedo, Denise B.; Dutra, Alberto S.

Estudo comparativo da cadeia produtiva florestal das regiões de Lages e de Pelotas...

destacam-se algumas particularidades na cadeia em desenvolvimento, as quais necessitam acompanhamento detalhado dos agentes envolvidos.

Ressalta-se que, ao se tratar da Região de Pelotas, utiliza-se a classificação do Atlas de Desenvolvimento Humano no Brasil, adaptada de acordo com os investimentos já realizados pela empresa Votorantim Celulose e Papel (VCP). Assim, englobam-se os municípios da região onde a empresa está se instalando, bem como aqueles que fazem parte do Programa de Fomento ao Plantio de Florestas da referida empresa (VCP, 2006). Esse programa compreende os municípios de Arroio Grande, Canguçu, Capão do Leão, Cerrito, Cristal, Jaguarão, Herval, Morro Redondo, Pedro Osório, Pelotas e São Lourenço do Sul.

A região em estudo está localizada na metade sul do Rio Grande do Sul, a qual se encontra em dificuldades econômicas e sociais, pois apresenta baixo crescimento do Valor Agregado Bruto e do emprego em todos os setores. Esse fato faz com que a região venha perdendo posições em termos de significância no estado (SCP/RS, 2005). Lima (2005, p. 11) destaca que a região já ocupou outra posição dentro da estrutura econômica do Rio Grande do Sul, uma vez que foi majoritariamente responsável pela produção econômica do estado, em outros momentos históricos.

Para Ilha et al. (2002), a decadência do ciclo do charque desencadeou um processo de declínio da participação econômica dessa região em relação ao estado. Esse declínio acentuou-se e diminuiu a população, a renda, as indústrias e a capacidade de desenvolvimento regional. Aliado a isso, tem-se o fato de que a Região de Pelotas, após essa decadência, não obteve êxito no ingresso em outro grande ciclo econômico, o que justifica, conforme salientam os autores acima citados, as iniciativas na busca de alternativas de reconversão em toda a metade sul do Rio Grande do Sul.

Pode-se observar que a taxa de crescimento da renda per capita real da região foi cerca de $15,20 \%$, abaixo da média estadual, a qual permaneceu na casa dos 37\% (PNUD, 2006). Essa situação conjuntural reflete-se em um esforço governamental, ao criar alternativas de desenvolvimento para a Região de Pelotas. De acordo com a SCP/RS (2002), o Governo do 
Estado contratou um plano de desenvolvimento amplo, o qual engloba, entre outras ações, a implantação do setor de base florestal no local que conglomera a Região de Pelotas/RS.

De igual modo, a portaria $n^{\circ} 275$ da Secretaria da Agricultura e Abastecimento do Rio Grande do Sul (SAA/RS, 2006), de 4 de junho de 2003, criou um grupo de trabalho com objetivo de incrementar o florestamento industrial no Rio Grande do Sul. A equipe integra o projeto Proflora, lançado pelo Governo do Estado para financiar ações de florestamento econômico e gerar, até 2014, receita bruta de $\mathrm{R} \$ 200$ milhões para os produtores.

De acordo com informações apresentadas por Ziebell (2006) na Câmara de Comércio de Rio Grande, a VCP já adquiriu 90.000 hectares de terras em 14 municípios da Região Sul do Rio Grande do Sul para a implantação de uma base florestal. Já foram plantados 24.000 hectares em áreas próprias e 2.700 hectares em terras de terceiros, por meio do Programa Poupança Florestal. O investimento já realizado é de R $\$ 310$ milhões e gerou 3.500 empregos (1.000 diretos e 2.500 indiretos). A previsão de início da produção na fábrica, a qual ainda depende de aprovação pelo conselho da empresa em 2009, está prevista para 2011, quando as primeiras florestas plantadas serão cortadas.

O ciclo médio do plantio ao corte das florestas situadas em áreas próprias e da poupança florestal é de 7 anos. Nos contratos de Poupança Florestal, o mínimo são 2 ciclos de plantio. É acordada a venda para a VCP de, no mínimo, 95\% da floresta, ao final de cada ciclo (VCPPoupança Florestal, 2006).

\section{Referencial teórico}

\subsection{Desenvolvimento regional: uma perspectiva da implantação em setores agrícolas diversificados}

Mais do que unicamente satisfazer a esfera individual, é possível a aplicação de uma estratégia com vistas a melhorias nos aspectos socioeconômicos de uma determinada região. Ganhos obtidos por uma empresa podem se refletir em geração de emprego e renda na localidade 
Elias, Sandro A.; Rathamann, Regis; Azevedo, Denise B.; Dutra, Alberto S.

Estudo comparativo da cadeia produtiva florestal das regiões de Lages e de Pelotas...

em que esta esteja situada, bem como em aumento de arrecadação pelo setor público, mediante o aumento da base de impostos. Logo, em se pensando numa estratégia setorial, pode-se aferir que esta seja uma possível forma de se obter desenvolvimento regional, perante efeitos multiplicadores de renda.

Antes de se conceituar o desenvolvimento regional, deve-se inserir o conceito de região. Para Bassan e Stendenberg (2003), região é um espaço com características naturais específicas, que, ao longo de seu processo de formação histórico-cultural, configurou uma identificação social, econômica, política e cultural, a fim de atender às necessidades de sua população, delimitando uma identidade regional própria. Por sua vez, o desenvolvimento regional, segundo Boisier (1996), é um processo localizado de troca social sustentada e que tem como finalidade última o progresso social permanente da região, da comunidade regional como um todo e de cada indivíduo residente nela. De tal modo, para que ocorra desenvolvimento regional, é imprescindível a acumulação primária de um processo de crescimento econômico, agregada à autonomia regionalizada de decisão por seus governantes. Da mesma forma, o desenvolvimento regional precisa, aproveitar suas vocações regionais e vantagens comparativas, fomentando-as por políticas especificas ao lócus.

Já o desenvolvimento local é aquele obtido a partir de uma rede de relações que permitem a consolidação de mecanismos de integração entre os atores, os quais possibilitam a evolução de um sistema produtivo. Esse se diferencia do desenvolvimento regional também por ser de caráter mais micro, ou seja, pode-se dizer que neste estudo, pretende-se avaliar os possíveis impactos da implantação do setor de base florestal na Região de Pelotas. No entanto, uma política, tanto de desenvolvimento regional quanto local, deve ser constituída com base na realidade local e precisa evitar o erro de aplicabilidade geral em políticas de desenvolvimento globais. Face à imensa diversidade inter-regional (cultural, histórica e econômica), a estratégia para a redução das desigualdades é diversa, logo, deve estar centrada na aplicação às vocações regionais.

Segundo Valentim (2003, p. 211), "um fator de crescimento, desenvolvimento e de aperfeiçoamento tecnológico são as externalidades geradas pela acumulação de capital humano que se manifestam, por exemplo, no nível de educação acumulado de uma determinada 
sociedade". Essas externalidades, por fim, são as únicas capazes de endogenizar o desenvolvimento, em virtude de que tornam capacitados os agentes locais, levando, por conseguinte, à superação da necessidade de exogeinização tecnológica. Ferreira (2001) aponta para a importância da agricultura como dinamizadora em regiões atrasadas, as quais, por sua vez, devem apostar em estratégias locais de desenvolvimento que visem à introdução de estruturas/cadeias produtivas diversificadas.

A estratégia descrita se torna necessária quando as demais alternativas de expansão de mercados tornam-se insuficientes, devido à falta de dinamismo de potenciais mercados demandantes para determinados produtos. Tal estratégia pode significar um leque de possibilidades de dinamização para a agricultura (Azevedo, 2000). Pensando-se num cenário de globalização econômica, onde se inserem os mercados atuais, a ampliação do dinamismo dos negócios, bem como a melhoria do desempenho de toda a estrutura produtiva, é vital tanto para a sobrevivência da agricultura, quanto para outros setores produtivos. A competitividade, definida como a capacidade sustentável de sobreviver e, de preferência, de crescer nos mercados correntes ou em novos mercados, impõe agregar à natureza agrícola a ideia de transmutar-se em uma empresa.

Para tanto, uma das principais competências que devem estar presentes no setor é a capacidade de coordenação de suas atividades. Esta pode ser definida como a capacidade de receber, processar, difundir e utilizar informações, de modo a definir e viabilizar estratégias competitivas ao longo de todo o processo produtivo. Essas estratégias competitivas, muitas vezes, têm como instrumento a inovação em produto, em processo, diferenciação e diversificação (Jank e Nassar, 2000).

\subsection{A análise de Cadeias Produtivas Agroindustriais (CPA) e de Filiére no setor de base florestal}

$\mathrm{Na}$ busca de gerar um aporte teórico que possibilite tanto o desenho da cadeia produtiva de base florestal que vem sendo implantada na Região de Pelotas/RS, quanto a avaliação dessa em relação àquela existente na Região dos Campos de Lages/SC, será utilizada a referência de 
Elias, Sandro A.; Rathamann, Regis; Azevedo, Denise B.; Dutra, Alberto S.

Estudo comparativo da cadeia produtiva florestal das regiões de Lages e de Pelotas...

Batalha (2001). Nesta, é feita uma equivalência entre as ideias de Cadeias Produtivas Agroindustriais (CPA) e de Filière. A escolha por essa referência específica deve-se à estruturação da cadeia a partir de três macrossegmentos, detalhados mais à frente, de modo a permitir uma visão mais detalhada da cadeia produtiva em estudo.

Mesmo havendo uma opção pelas ideias de CPA apresentadas por Batalha (2001), alguns autores ajudam no estabelecimento mais preciso do conceito de cadeia produtiva. Na visão de Castro et al. (1995, p. 12),

[...] cadeias produtivas são conjuntos de componentes interativos, tais como sistemas produtivos agropecuários e agroflorestais, fornecedores de serviços e insumos, indústrias de processamento e transformação, distribuição e comercialização, além de consumidores finais do produto e subprodutos da cadeia.

Os estudos de Morvan (1991) indicam quatro grandes utilizações para a noção de Filière de Produção: (i) como uma ferramenta de descrição técnico-econômica: a dimensão técnica está correlacionada à descrição dos desenvolvimentos necessários à elaboração de um produto final e à dimensão tecnológico-econômica, correlacionada ao conhecimento das estruturas de produção; (ii) como uma modalidade de recorte do sistema produtivo: a noção de Filière permite fazer recortes distintos do sistema de análise, dependendo dos objetivos desta, podendo-se usar como referência para esse entendimento os quesitos apresentados por Rainelli (1991), os quais lembram que esse recorte pode ser feito a partir de matéria-prima, de um estado intermediário, de uma grande função ou de um produto geral; (iii) como um método de análise da estratégia das firmas: este pode se dar em termos de estrutura, em que a finalidade reside na busca de uma compreensão das limitações técnico-econômicas, assim como pode se dar em termos de comportamento, em que se privilegia a função dos atores, permitindo-se a análise da estratégia; (iv) como um instrumento de política industrial: em nível de nação, a Filière de Produção serve, geralmente, como uma referência original para a definição de políticas industriais. Isso ocorre porque a estratégia de Filière conduz a raciocinar em termos de estruturas globais. 


\subsection{Visão sistêmica e a complexidade do ambiente englobante ao setor de base florestal}

As cadeias produtivas agroindustriais, como é o caso do objeto deste estudo, inserem-se em um ambiente de diversidade e de multiplicidade, no qual os inter-relacionamentos são cada vez mais complexos. Logo, aos atores impõe-se a necessidade de um olhar sistêmico, ou seja, de perceber, no ambiente englobante, as variáveis necessárias para a minimização do risco inerente aos seus negócios.

O conceito sistêmico, segundo Morin (1987), exprime simultaneamente unidade, multiplicidade, totalidade, diversidade, organização e complexidade. A concepção situa-se imediatamente para lá do reducionismo e do holismo, e apela para um princípio de inteligibilidade que integra a parte de verdade incluída num e noutro: não deve haver aniquilamento do todo pelas partes, nem das partes pelo todo. Importa, portanto, esclarecer as relações entre as partes e o todo, e como cada termo remete ao outro.

Tudo isso decorre do fato de que setores produtivos, como o de base florestal, estão inseridos, conforme Bertalanffy (1976) e Luhmann (1997), em sistemas abertos. Dessa maneira, estão sujeitos a constantes trocas de fluxos com o ambiente. Em consequência, deve-se ter uma definição clara de seus limites, pois sua finalidade é a sua sobrevivência no mercado. Para tanto, os atores do setor devem conhecer seus elementos internos, a atuação destes e como estes se inter-relacionam.

\subsection{O processo de desenvolvimento como consequência da diversificação de cadeias produtivas e de visão sistêmica de seus atores}

Pode-se perceber, a partir dos referenciais teóricos apresentados, que o desenvolvimento de uma determinada região é um processo cumulativo, de necessidades tanto macro - aquelas que dependem de uma conjugação de atores e/ou fatores -, quanto de necessidades micro - aquelas que dependem de aspectos individuais -, os quais se referem aos indivíduos, atores ou firmas isoladas. Mais do que isso, o desenvolvimento regional passa, necessariamente, por um processo inicial localizado: o desenvolvimento local. No estudo em questão, o desenvolvimento regional 
Elias, Sandro A.; Rathamann, Regis; Azevedo, Denise B.; Dutra, Alberto S.

Estudo comparativo da cadeia produtiva florestal das regiões de Lages e de Pelotas...

remete às Regiões dos Campos de Lages/SC e de Pelotas/RS como um todo, enquanto o local focaliza o desenvolvimento especifico dos municípios de Lages e de Pelotas.

Assim, conforme a Figura 2, o desenvolvimento regional decorre de um processo de desenvolvimento localizado nos municípios individualmente, no caso, chamado de local. Para que este desenvolvimento ocorra, a visão sistêmica dos atores envolvidos na cadeia produtiva de base florestal é uma etapa necessária, mas não única; também é exigida a diversificação produtiva que essa possa representar na região que esteja em implantação.

A primeira etapa refere-se ao fato de que é necessária, para os atores que compõem a cadeia produtiva, uma visão sistêmica do ambiente no qual estejam inseridos, bem como o conhecimento do seu caráter complexo. A segunda etapa remete ao fato de que regiões atrasadas devem apostar em estratégias locais de desenvolvimento, que visem à introdução de estruturas produtivas diversificadas, ou seja, cadeias produtivas diferenciadas. Cabe fazer menção ao que aponta Ferreira (2001): a estagnação, ou o atraso de uma determinada região, pode ser medida pelas variações dos Índices de Desenvolvimento Humano dos municípios que a compõem; essas variações devem apresentar taxas inferiores às médias de variação das demais regiões que compõem o estado que a engloba.

\section{Metodologia}

Este artigo apresenta caráter exploratório, que consiste em, de acordo com Santos (2000), um levantamento de características conhecidas, componentes de um fato, fenômeno ou problema. Como fonte de informação complementar, foram utilizados dados secundários coletados junto ao Programa das Nações Unidas para o Desenvolvimento (PNUD, 2006), os quais estão disponíveis em seu Atlas do Desenvolvimento Humano no Brasil, bem como pesquisa bibliográfica sobre o setor de base florestal e contexto histórico e econômico das regiões estudadas. Além disso, utilizaram-se abordagens sobre desenvolvimento regional, desenvolvimento local, Filiére e visão sistêmica. 
A coleta dos dados primários foi realizada durante visita técnica à Universidade do Planalto Catarinense (UNIPLAC) e à unidade de geração de energia da empresa TRACTEBEL, ambas localizadas no Município de Lages/SC, nos dias 25 e 26 de agosto de 2006. Para a análise de dados, inicialmente, foram agrupadas séries de dados econômicos e sociais, com o intuito de responder ao objetivo proposto neste trabalho, qual seja, o de analisar, em comparação, a cadeia produtiva de base florestal instalada na Região dos Campos de Lages/SC, com aquela que está se configurando na Região de Pelotas/RS, em termos de perspectiva de potencialidades do desenvolvimento regional e local nesta última. Nesse sentido, a Figura 2, retrata este processo.

Figura 2: Consolidação macro e micro das necessidades para a futura obtenção de desenvolvimento regional.

Figure 2: Macro and micro needs consolidation for the future acquisition of regional development.

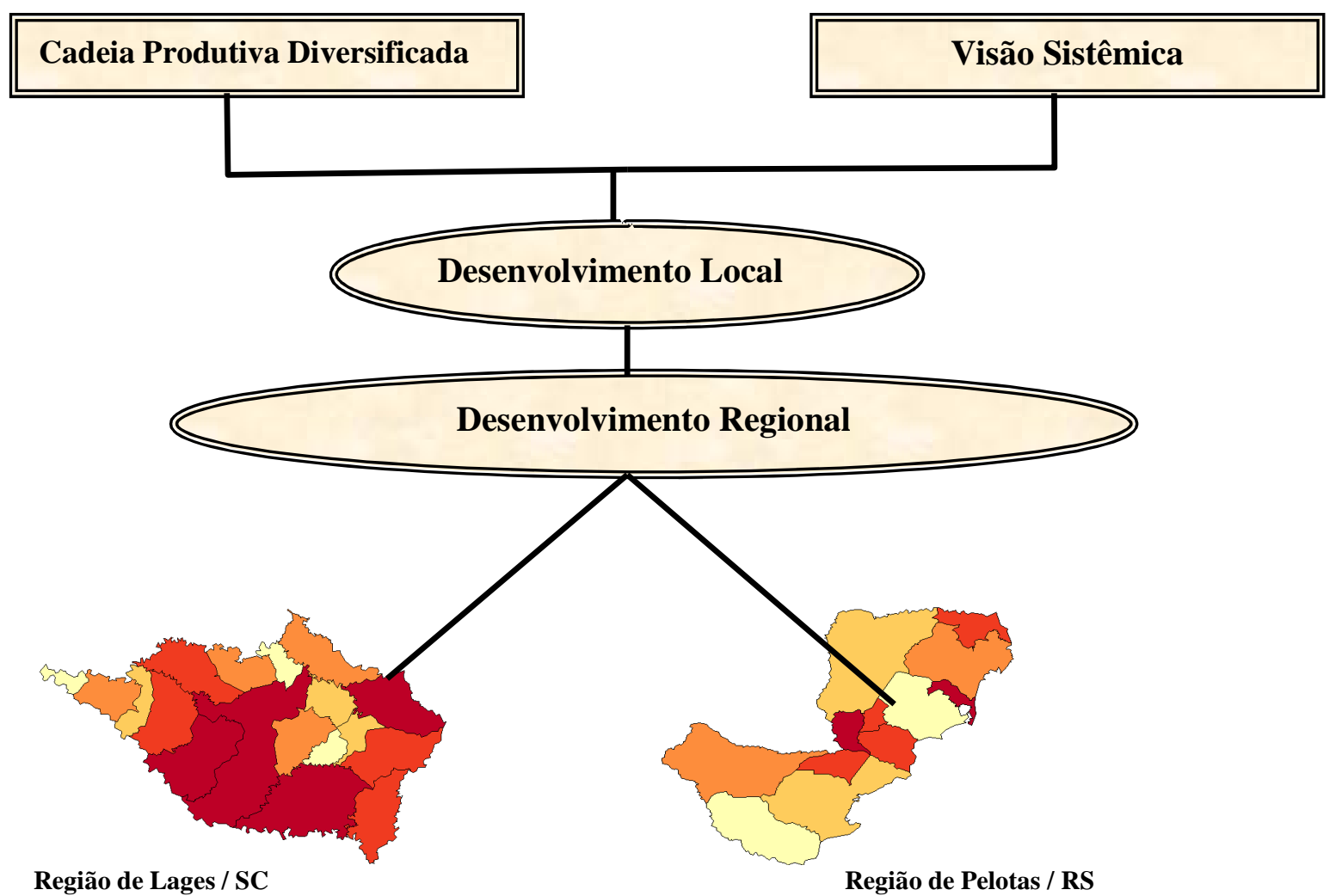

Pretende-se, com isso, responder se há correlação entre o desenvolvimento/não desenvolvimento regional e a inserção/não inserção do setor de base florestal nos municípios 
Elias, Sandro A.; Rathamann, Regis; Azevedo, Denise B.; Dutra, Alberto S.

Estudo comparativo da cadeia produtiva florestal das regiões de Lages e de Pelotas...

estudados, com a utilização, para tanto, do ferramental da análise de correlação da estatística econômica.

Por fim, foi calculado, para a Região dos Campos de Lages/SC, o Índice do Desenvolvimento Humano (IDHm) para o ano de 2003, com o intuito de verificar se vem se mantendo o desenvolvimento econômico da região para, em consequência, verificar em que medida os resultados podem ser transmutáveis para a Região de Pelotas/RS.

\section{Resultados}

O desenvolvimento de uma determinada região é um processo cumulativo, de necessidades macro, microrregionais e microeconômicas. Geralmente, esse processo apresenta resultados em longo prazo, motivo pelo qual se procurou comparar uma região com tradição no setor de base florestal com uma em que a implantação seja incipiente.

Inicialmente, analisou-se se o setor é responsável, e em que medida, pelo desenvolvimento regional e local da Região dos Campos de Lages/SC. Mais do que isso, se procurou diferenciar o processo de crescimento econômico daquele no qual este reverte em melhorias de qualidade de vida para a população local, o que a teoria convenciona chamar de desenvolvimento local. Posteriormente, mediante a análise dos dados e aspectos observados na visita técnica ao Município de Lages/SC, buscou-se identificar os fatores condicionantes da existência desse processo. Preliminarmente, a consolidação do referencial teórico apontou como fatores condicionantes um conjunto complexo de aspectos, a saber, a visão sistêmica dos atores envolvidos na cadeia produtiva de base florestal em consonância com a introdução da diversificação produtiva.

Por fim, diante dos resultados obtidos, procurou-se verificar se os efeitos alcançados na Região dos Campos de Lages/SC, com a presença do setor de base florestal, são aplicáveis à Região de Pelotas/RS. Em busca da obtenção de maior embasamento para a análise dos resultados, desenhou-se, ainda que em caráter preliminar, a provável configuração da cadeia produtiva de base florestal que está se formando na Região de Pelotas/RS. 


\subsection{Impactos econômico-sociais da presença do setor de base florestal na Região dos Campos de Lages/SC}

Pode-se observar que, entre 1994 e 2003, houve um significativo crescimento do valor bruto da produção oriunda do setor de base florestal da Região dos Campos de Lages/SC. Estes são frutos, de acordo com Brand e Neves (2005), tanto da melhor organização da cadeia produtiva, como da profissionalização dos empresários ligados ao setor. Esses fatores se aliam a uma demanda interna e externa crescente pelos produtos finais gerados pela cadeia. Deve-se mencionar que a escolha pelo período de análise - de 1994 a 2003 - deve-se ao fato de que este representa o início do processo de estabilização da economia brasileira. A estabilização econômica permite, de uma forma geral, que todos os setores produtivos da economia estejam menos suscetíveis às vulnerabilidades externas e internas. Também facilita a análise, em termos econômicos, pela presença de uma única moeda em todo o período: o Real.

Ao lado desses fatos, há um acentuado crescimento da renda per capita da população da região, a qual triplica no período analisado. Assim, ao se iniciarem as respostas às questões de pesquisa, buscou-se avaliar a existência de correlações entre as variáveis analisadas. Em função disso, foi realizado teste de correlação entre a renda per capita e o valor bruto da produção da região em foco. Os resultados constam no Quadro 1, os quais se analisam a seguir.

Interpretando os resultados demonstrados no Quadro 1, pode-se verificar que, com um intervalo de confiança de $95 \%$, em 63,8\% dos casos, a variação da renda per capita da Região dos Campos de Lages/SC é explicada pela variação do valor bruto da produção do setor de base florestal da região. Além disso, mediante o uso de teste de verificação de autocorrelação serial de Durbin Watson, aceitou-se H0. Logo, não há autocorrelação na série de dados analisada. Os testes de significância dos betas revelaram que os valores são estatisticamente significantes. Ainda, o exame desses valores permite aferir que as variáveis são diretamente proporcionais, ou seja, a renda per capita cresce com a produção do setor.

Com tais resultados, pode-se interpretar que o crescimento da renda per capita da região, o qual sobe entre 2002 e 2003 em cerca de 15,7\%, e praticamente triplica entre 1994 e 2003, tem 
Elias, Sandro A.; Rathamann, Regis; Azevedo, Denise B.; Dutra, Alberto S.

Estudo comparativo da cadeia produtiva florestal das regiões de Lages e de Pelotas...

como uma das variáveis explicativas o crescimento do valor bruto auferido com a produção do setor de base florestal.

Quadro 1: Resultado do teste de regressão realizado entre a renda per capita e o valor bruto da produção do setor de base florestal da Região dos Campos de Lages/SC.

Chart 1: Result of the regression test performed between the per capita income and the gross value of production of the Campos de Lages/SC region's forest-based sector.

Modelo - renda per capita e valor bruto da produção

$$
\text { Yi }=3329,85+0,016 \text { xi }
$$

Coeficiente de determinação r2: 0,6384

Coeficiente múltiplo: 0,7990

Teste Durbin Watson para amostras pequenas: Aceita H0 (não há autocorrelação serial)

No entanto, esse índice indica crescimento econômico ${ }^{1}$, o que não significa que o ganho tenha se refletido em melhorias sociais, ou seja, que tenha se convertido em desenvolvimento econômico ${ }^{2}$. Para tanto, procurou-se verificar se esse ganho produziu melhorias para a população da Região dos Campos de Lages/SC. Utilizou-se, para isso, o Índice de Desenvolvimento Humano $^{3}$ da Organização das Nações Unidas (ONU, 2003). Pode-se verificar uma tendência de crescimento do referido indicador de desenvolvimento. Fica evidenciado o fato de que o aumento da renda per capita entre os anos 2000 e 2003 (cerca de 25\%) é determinante da variação positiva no IDH de cerca de 9,33\%, principalmente em função de os demais subíndices manterem-se constantes, face o último Censo no Brasil datar do ano 2000 (ver Tabela 1). 
Tabela 1: Renda per capita, taxa de analfabetismo, taxa de alfabetização e Índice de Desenvolvimento Humano (IDM) médios na Região dos Campos de Lages/SC, 1991, 2000 e 2003.

Table 1: Average per capita income, illiteracy rate, literacy rate and the Human Development Index (HDI) in the Campos de Lages/SC region, 1991, 2000 and 2003.

\begin{tabular}{l|c|c|c|c}
\hline & $\mathbf{1 9 9 1}$ & $\mathbf{2 0 0 0}$ & $\mathbf{2 0 0 3}$ & \% variação \\
\hline Renda per capita real (mês) & 122,66 & 198,38 & 247,97 & 25,00 \\
\hline IDH-Renda & 0,57 & 0,65 & $0,83^{*}$ & 27,69 \\
\hline IDH-Longevidade & 0,71 & 0,77 & $0,77^{* *}$ & 9,70 \\
\hline IDH-Educação & 0,723 & 0,83 & $0,83^{* *}$ & 14,98 \\
\hline IDH & 0,666 & 0,751 & 0,82 & 9,33 \\
\hline
\end{tabular}

** Mantidos valores para o ano de 2003 em função de não ter sido realizado Censo Populacional desde 2001.

No entanto, deve-se relativizar a análise, pois a transformação de crescimento econômico em desenvolvimento não é um processo automático, ou seja, a ampliação da renda é um meio para se melhorar o acesso aos meios de subsistência, mas que, sozinha, não garante a melhoria da qualidade de vida. Ainda assim, de acordo com Valverde et al. (2003), é apontado que o setor em estudo tem como uma de suas virtudes acentuados efeitos multiplicadores sobre o restante da economia. Segundo esses autores, cada R \$ 1 mil reais investidos no setor geram cerca de R \$2,4 mil reais em produção, bem como cada emprego gerado demanda investimentos de cerca de $\mathrm{R} \$$ 10 mil reais, valor considerado pequeno frente a outros setores da economia.

A microrregião Campos de Lages possui tradicionalmente índices de desenvolvimento econômico e social abaixo da média do Estado de Santa Catarina. Todavia, conforme a Tabela 1, os indicadores analisados, entre os anos de 1991 e 2000, evoluíram mais que a média estadual, auxiliando na redução das desigualdades regionais.

\subsection{A implantação do setor de base florestal na Região de Pelotas/RS}

Os recentes investimentos realizados, bem como os projetos e intenções de investimentos futuros na cadeia florestal nessa região, por si só, são fatores que levarão a uma maior diversificação da matriz produtiva regional, o que já é significativo frente à carência de 
Elias, Sandro A.; Rathamann, Regis; Azevedo, Denise B.; Dutra, Alberto S.

Estudo comparativo da cadeia produtiva florestal das regiões de Lages e de Pelotas...

investimentos e de crescimento local. Porém, observou-se, preliminarmente, que a cadeia de base florestal que se configura na Região de Pelotas/RS é diferente, em virtude de suas especificidades regionais, da cadeia existente na Região dos Campos de Lages/SC. Em função disso, os resultados não podem ser perfeitamente transmutáveis entre regiões.

Tendo em vista a incipiente atividade de empresas de base florestal nessa região, as características atuais das florestas que estão sendo plantadas, e considerando que não haja mudanças na condução dessas florestas, as quais estão previstas para sofrerem corte raso no sétimo ano, foi desenhado um esboço de como poderá ser construída a cadeia que está em formação na região, quando as indústrias de celulose e papel já estiverem instaladas, a partir de 2011.

Figura 3: Possível cadeia de base florestal da Região de Pelotas/RS, a partir de 2011.

Figure 3: Possible chain of Pelotas/RS forest-based region starting in 2011.

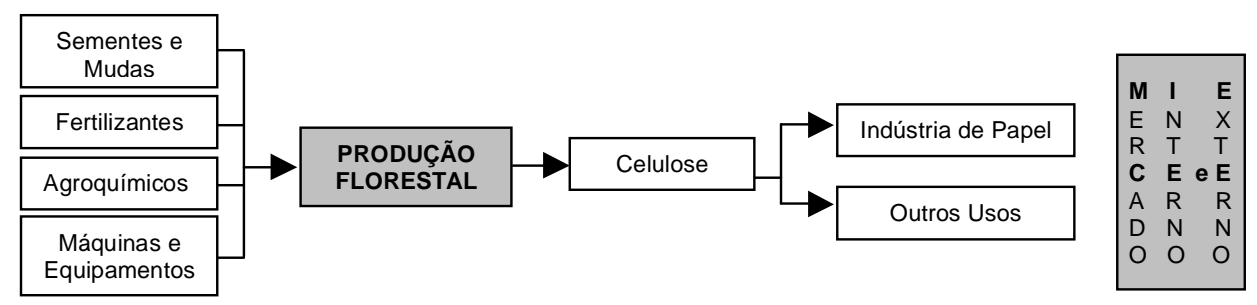

Como se pode verificar na Figura 3, a cadeia de base florestal da Região de Pelotas/RS, em um primeiro momento, desenvolverá apenas atividades voltadas à produção de papel e celulose. Esses investimentos já denotam uma nova configuração no contexto dos arranjos produtivos inerentes a essa região.

Entretanto, em termos de geração de desenvolvimento local e, em uma esfera mais macro, desenvolvimento regional, outros fatores deverão estar aliados a esses investimentos, quais sejam: (i) investimentos na diversificação de atividades dentro da própria cadeia de base florestal; (ii) estabelecimento de parcerias com universidades e órgãos de pesquisa, no que tange ao desenvolvimento de estudos técnicos e econômicos sobre o setor, e (iii) com a gradativa expansão da cadeia, o olhar sistêmico sobre todos os elos, buscando a identificação de eventuais entraves 
que possam ser resolvidos em um estágio inicial, o que pode ser obtido pela análise do caso da cadeia florestal da Região dos Campos de Lages/SC.

Considerando-se os baixos níveis de incremento verificados, tanto na renda per capita, quanto nos índices IDH, entre os anos de 1991 e 2000, na Região de Pelotas/RS, se comparados aos índices apresentados pela Região dos Campos de Lages/SC, bem como a correlação positiva entre o valor bruto da produção e o crescimento da renda per capita daquela região (Quadro 1), presume-se que o desenvolvimento de atividades ligadas ao setor de base florestal na Região de Pelotas/RS possa alavancar seus índices de desenvolvimento humano. Esses índices poderão originar um crescimento mais robusto com a intensificação e diversificação das atividades dentro dessa cadeia.

\section{Considerações finais}

A cadeia de base florestal da Região de Lages/SC, considerando-se todo o seu histórico e evolução, apresenta-se atualmente em um estágio mais avançado de organização do que o verificado no início da década de 1990, uma vez que os agentes estão atuando com uma visão sistêmica mais ampla de seus negócios e da cadeia como um todo. O colapso no fornecimento de matéria-prima verificado nas décadas de 1970 e 1980, por sua vez, serviu de lição para esse setor, o qual tem se preocupado não somente com iniciativas de reflorestamento, mas também com os diferentes usos e destinos para os resíduos gerados. Racionaliza-se, dessa forma, a utilização de matéria-prima.

Estudos e pesquisas são direcionados para a agregação de valor de resíduos, até então descartados pelas empresas processadoras de madeira, fato que origina novos produtos destinados a novos nichos de mercado. Esses estudos e pesquisas destacam, também, o fato de que os resíduos de madeira, quando bem aproveitados, podem ser até mais lucrativos do que a própria madeira. A experiência e a vocação local fizeram da Região dos Campos de Lages/SC um dos maiores polos madeireiros do país, formado por diversificadas empresas que buscam, constantemente, (i) conhecimento e profissionalização, (ii) dinâmico setor prestador de serviços 
Elias, Sandro A.; Rathamann, Regis; Azevedo, Denise B.; Dutra, Alberto S.

Estudo comparativo da cadeia produtiva florestal das regiões de Lages e de Pelotas...

para as atividades de base florestal, (iii) instituições que investem em pesquisa técnica e econômica, bem como (iv) o engajamento do poder público.

Os Índices de Desenvolvimento Humano medidos pelo Programa das Nações Unidas para o Desenvolvimento (PNUD) demonstram que, a partir da retomada das atividades madeireiras nessa região, ocorrida no início da década de 1990, a região desenvolveu-se na esteira dos resultados obtidos pelo seu setor de base florestal. Os investimentos iniciais nesse mesmo setor, os quais estão sendo direcionados à metade sul do Rio Grande do Sul, mais especificamente para a Região de Pelotas/RS, certamente trazem perspectivas de benefícios econômicos para os municípios. Porém, para que se obtenha um sólido desenvolvimento regional, tão necessário para as regiões mais pobres, é fundamental a continuidade dos investimentos na diversificação de atividades dentro da própria cadeia de base florestal de Pelotas/RS, dando outros destinos à madeira, não somente o da fabricação de papel e de celulose.

A recente iniciativa da Região dos Campos de Lages/SC mostra também que o adequado processamento dos resíduos e sobras da madeira pode constituir-se em uma fonte de renda tão importante para o setor quanto a própria renda advinda do processamento da madeira. Sobras de madeira, que eram anteriormente descartadas pela suposta falta de utilidade, acabavam por acarretar problemas ambientais. Atualmente, dão origem a produtos de alto valor agregado, como móveis, e são utilizadas na produção de energia.

A evolução observada no setor de base florestal de Lages/SC demonstra que a busca por resultados e desenvolvimento de uma cadeia produtiva deve vir aliada a uma ampla visão das partes em relação ao todo, bem como do todo em relação às partes. Em suma, o papel da visão sistêmica tem se mostrado fundamental nesse processo.

Para a Região de Pelotas/RS, cabe aguardar por novos desdobramentos que determinarão, mais precisamente, os rumos a serem tomados pelo setor de base florestal dessa região. De acordo com as prospecções de investimentos de que se tem conhecimento, esse setor ainda está muito concentrado em apenas uma atividade: a produção de papel e celulose. 
Sendo assim, e considerando-se que a cadeia de base florestal representa a principal atividade econômica da Região dos Campos de Lages/SC, há mais de meio século, concluiu-se que não se podem transpor os dados de crescimento econômico e social da região de Santa Catarina para a região gaúcha. Isso se deve ao fato de que, na Região de Pelotas/RS, existem, ainda, apenas áreas com plantações de florestas e a configuração de sua cadeia pode ser somente prevista e projetada. Dessa forma, esses dados sugerem novos estudos, na medida em que os demais elos dessa cadeia forem sendo desenvolvidos.

\section{Referências}

ASSOCIAÇÃO BRASILEIRA DE PRODUTORES DE FLORESTAS PLANTADAS (ABRAF). 2006. Anuário estatístico da ABRAF: ano base 2005. Brasília, 87 p.

ABRAFLOR. 2006. Associação Brasileira dos Produtores de Florestas Plantadas. Anuário estatístico da ABRAF - Ano Base 2005. Disponível em: http://www.abraflor.com.br, acesso em: 25/09/2006.

AZEVEDO, P.F. 2000. Concorrência no Agribusiness. In: D. ZYLBERSZTAJN; M.F. NEVES (orgs), Economia e gestão dos negócios agroalimentares. São Paulo, Pioneira. 428 p.

BACHA, C.J.C. 2000. Cadeia madeira/móveis. In: D. ZYLBERSZTAJN; M.S. IANK; P.F. AZEVEDO; C.J.C. BACHA; I. HERRMANN; F.S. PEROBELLI; M.F. PAES LEME, Apoio a instalação dos Fóruns de Competitividade nas cadeias produtivas couro/calçados, têxtil, madeira/móveis e fertilizantes. São Paulo, PENSA, 38 p.

BASSAN, D.S.; STENDENBERG, D.R. 2003. Desenvolver buscando a redução das desigualdades. In: D.F. BECKER; M.L. WITTMANN (orgs), Desenvolvimento regional: abordagens interdisciplinares. Santa Cruz do Sul, Edunisc.

BATALHA, M.O. 2001. Sistemas agroindustriais: definições e correntes metodológicas. In: M.O. BATALHA, Gestão agroindustrial. $2^{\mathrm{a}}$ ed., São Paulo, Atlas, vol.1.

BERTALANFFY, L.V. 1976. Teoria General de los Sistemas. México, Fondo de Cultura Econômica, 311 p.

BOISIER, S. 1996. Modernidad y território. Cuadernos del ILPES, 42. Santiago de Chile, Instituto Latinoamericano y del Caribe de Planificación Económica y Social-ILPES.

BRAND, M.A; NEVES, M.D. 2005. Levantamento da disponibilidade dos resíduos industriais e florestais de madeira e avaliação da variação de sua qualidade energética em função das 
Elias, Sandro A.; Rathamann, Regis; Azevedo, Denise B.; Dutra, Alberto S.

Estudo comparativo da cadeia produtiva florestal das regiões de Lages e de Pelotas...

condições climáticas anuais, na região de Lages - Santa Catarina. Relatório técnico. Lages, Universidade do Planalto Catarinense.

CASTRO, A.M.G.; COBBE, R.V.; GOEDERT, W.J. 1995. Prospecção de demandas tecnológicas - Manual metodológico para o SNPA. Empresa Brasileira de Pesquisa Agropecuária. Departamento de Pesquisa e Difusão de Tecnologia. Brasília, Embrapa-DPD, 82 p.

COSTA, L. 1982. O Continente das Lagens. Florianópolis, Fundação Catarinense de Cultura, vol. 2, $20 \mathrm{p}$.

FERREIRA, E.F. 2001. Estudo do programa de fruticultura irrigada de clima temperado, da região da campanha do Rio Grande do Sul, através do sistema integrado agronegocial. Bagé, RS. Dissertação de Mestrado. URCAMP.

FREITAS, A.R. 2005. As perspectivas da cadeia de negócios da madeira no sul do Brasil. In: SEMINÁRIO CATARINENSE DE REFLORESTAMENTO, 1, Concórdia, 2005. Anais... Concórdia. Disponível em http://www.sbs.org.br/, acesso em: 26/02/2006.

HOFF, D.N.; SIMIONI, F.J. 2005. O setor de base florestal na serra catarinense. Lages, Editora Uniplac, $254 \mathrm{p}$.

GOURLATI FILHO, A. 2002. Formação econômica de Santa Catarina. Florianópolis, Cidade Futura, 504 p.

ILHA, A.S.; ALVES, F.D.; SARAIVA, L.H.B. 2002. Desigualdades regionais no rio grande do sul: o caso da metade sul. In: ENCONTRO DE ECONOMIA GAÚCHA, Porto Alegre, 2002. Anais... Porto Alegre. Disponível em: Www.fee.rs.gov.br/sitefee/download/eeg/1/mesa_3_ilha _alves_saravia.pdf, acesso em: 30/9/2006.

JANK, M.S.; NASSAR, A.M. 2000. Competitividade e globalização. In: D. ZYLBERSZTAJN; M.F. NEVES (orgs), Economia e gestão dos negócios agroalimentares. São Paulo, Pioneira, 428 p.

LIMA, A.E.M. 2005. A indústria e a economia regional no Rio Grande do Sul: formação histórica e evolução recente (1990/2000). In: ENCONTRO DE ECONOMIA GAÚCHA FEE, 2, Porto Alegre, 2005. Anais... Porto Alegre, FEE. Disponível em: http://www.fee.tche.br/sitefee/pt/content/eeg/index.php, acesso em: 28/09/2006.

LUHMANN, N. 1997. Sociedade y sistema: la ambición de la teoria. Buenos Aires, Ice, 144 p.

MORIN, E. 1987. O Método I: A Natureza da Natureza. Mira-Sintra, Mem Martins, 155 p.

MORVAN, Y. 1991. Filière de production. In: Y. MORVAN, Fondements d'economie industrielle. $2^{\mathrm{a}}$ ed., Paris, Econômica, 639 p. 
ORGANIZAÇÃO DAS NAÇÕES UNIDAS (ONU). 2003. Programa das Nações Unidas para o Desenvolvimento. Desenvolvimento humano e IDH. New York, Oxford University Press. Disponível em: http://www.pnud.org.br/idh, acesso em: 06/08/2006.

PROGRAMA DAS NAÇÕES UNIDAS PARA O DESENVOLVIMENTO (PNUD). 2006. Atlas do Desenvolvimento Humano no Brasil. Disponível em: www.pnud.org.br/atlas, acesso em: 26/09/2006.

RAINELLI, M. 1991. Les Filières de production. In: R. ARENA; L. BENZONI; J. de BRANDT; P. ROMANI, Traitè d'economie industrielle. $2^{\mathrm{a}}$ ed., Paris, Economica, p. 222-226.

RAMBO, S.J.B. 1956. A fisionomia do Rio Grande do Sul. Porto Alegre, Selbach, 456 p.

SANTOS, A.R. 2000. Metodologia científica: a construção do conhecimento. $3^{\mathrm{a}}$ ed., Rio de Janeiro, DP e A Editora, 144 p.

SECRETARIA DE AGRICULTURA E ABASTECIMENTO DO RIO GRANDE DO SUL (SAA/RS). 2006. Programa Estadual de Florestamento. Disponível em: http://www.saa.rs.gov.br/saa/html/saa_programas_novo.htm\#06, acesso em: 30/9/2006.

SBS. 2003. PROPFLORA e PRONAF Florestal: Situação Atual e Perspectivas. Financiamento Para Pequenos e Médios Produtores Florestais: Situação Atual e Perspectivas Relatório do Workshop realizado na SBS em 20 de março de 2003. Sociedade Brasileira de Silvicultura. Disponível em: http://www.sbs.org.br/destaques_PROPFLORAepronaf.htm, acesso em: 19/9/2006.

SECRETARIA DE COORDENAÇÃO E PLANEJAMENTO DO RIO GRANDE DO SUL (SCP/RS). 2005. Projeto Rumos 2015: Estudo sobre Desenvolvimento Regional e Logística de Transportes no RS. Disponível em: http://www.ufrgs.br/propesq/forum/publicacoes/rumos2015 .htm, acesso em: 25/09/2006.

SECRETARIA DE COORDENAÇÃO E PLANEJAMENTO DO RIO GRANDE DO SUL (SCP/RS). 2002. Atlas Socioeconômico do Rio Grande do Sul. Disponível em http:// http://www.scp.rs.gov.br/ATLAS/atlas.asp, acesso em 25/09/2006.

UNITED NATIONS. 2005. Global challenge global opportunity: trends in sustainable development. Disponível em: http://www.un.org, acesso em: 14/12/2005.

VALENTIM, R. 2003. O capital social como um dos elementos que compõe a dinâmica do desenvolvimento regional. In: D.F. BECKER; M.L. WITTMANN (orgs.), Desenvolvimento regional: abordagens interdisciplinares. Santa Cruz do Sul, EDUNISC, 256 p.

VALVERDE, S.R; OLIVEIRA, G.G; CARVALHO, R.M.A.M.; SOARES, T.S. 2003. Efeitos multiplicadores da economia florestal brasileira. Revista Árvore, 27(3):285-293. 
Elias, Sandro A.; Rathamann, Regis; Azevedo, Denise B.; Dutra, Alberto S.

Estudo comparativo da cadeia produtiva florestal das regiões de Lages e de Pelotas...

VCP-POUPANÇA FLORESTAL. 2006. Perguntas e Respostas. Disponível em http://www.vcp.com.br/sitevcp/poupancaflorestal/perguntasrespostas.html, acesso em: 29/09/2006.

VCP. 2006. Semeando o Futuro. Disponível em: http://www.vcp.com.br/NR/ rdonlyres/B199811F-7823-4534-BFB8-6D531FE35E6A/13298/VCPhandout2005PORT.ppt, acesso em: 21/08/2006.

ZIEBELL, C.2006. Celuloseonline. Disponível em: http://www.celuloseonline.com.br/pagina /pagina.asp?IDItem=10592\&IDNoticia=8302, acesso em: 11/05/2006.

\footnotetext{
${ }^{1}$ Conceito que mensura o ganho econômico propriamente dito, em termos de renda.

${ }^{2}$ Conceito que é usado quando os ganhos econômicos transformaram-se em ganhos sociais.

${ }^{3}$ É a base do Relatório de Desenvolvimento Humano (RDH), publicado anualmente pela Organização das Nações Unidas. Parte, do pressuposto de que para mensurar desenvolvimento, não se deve apenas considerar dimensão econômica, mas também as características sociais, culturais e políticas que influenciam a qualidade da vida humana. Para isso, procura avaliar três componentes básicos do desenvolvimento: renda, longevidade e educação. O referido índice varia de 0 a 1 , e, quanto mais próximo de 1, maior é o desenvolvimento alcançado. O desenvolvimento é indicado mediante a média de três grandes subíndices: produto interno bruto (IDH-RENDA), educação (IDH-EDUCAÇÃO) e esperança de vida (IDH LONGEVIDADE).
} 